\title{
Conclusiones de la Reunión Internacional sobre Puertos Fluviales Antiguos: Ciudad, Desarrollo e Infraestructuras
}

En España, la arqueología subacuática es una disciplina relativamente joven por lo que, salvo destacadas excepciones, la inexperiencia española y concretamente la valenciana debe ser dispensada. Todavía, hoy por hoy, muchas de las noticias sobre patrimonio arqueológico sumergido nos llegan fruto de dragados, con toda la problemática de contextualización, etc. que se puso de manifiesto en el río Arade, fruto de expoliaciones, o en el mejor de los casos, fruto de la casualidad y no de una investigación sistemática. Esto nos lleva a posteriores problemas de interpretación como los que perfectamente expusieron en la comunicación sobre Hispalis $\mathrm{O}$, en el caso del mar, a tantos y tantos barcos. Probablemente esto se deba, entre otras cosas, a la falta de formación de profesionales capacitados para realizar los trabajos que requiere una intervención en un medio acuático para poder realizar intervenciones como la que se ha llevado a término en Sagunto. En este sentido, plenamente conscientes de la necesidad de sistematizar estos trabajos, creemos que corresponde a las instituciones académicas por una parte y a los diferentes centros de arqueología subacuática autonómicos, el papel de ofrecer esta formación con el fin de crear la inquietud necesaria y equipos de arqueólogos capaces de acometer cualquier proyecto de arqueología acuática.

Por otra parte, tal y como pudimos escuchar a lo largo de las jornadas, existen muchas similitudes entre todos estos puertos. Los grandes Imperios siempre han prestado una especial atención al correcto funcionamiento de sus puertos. Pudimos ver cómo Roma empleaba un esfuerzo muy importante en asegurarse el aprovisionamiento necesario para mantener toda la maquinaria que lo movía o cómo los Mayas dependían, en gran medida, de los intercambios vía fluviomarítima para conseguir esa homogeneidad cultural que los caracterizó. Así pues, buena parte de las ciudades más importantes se han constituido como tales precisamente a partir de sus puertos, caso de Arles como punto de encuentro entre Italia, Hispania y el interior de la Galia. Pensamos en Aquileia y en esa organización tan compleja y plurifuncional y recordamos la Albufera de Valencia, a la que pocas veces se le ha dado la importancia que merece en el marco de los intercambios. Sin duda a partir de este congreso todos los arqueólogos vamos a observarla desde otra perspectiva.

Una característica muy común a todos ellos han sido los cambios geomorfológicos tan drásticos que ha sufrido el paisaje debido a que el litoral y los cursos fluviales son ambientes muy variables por naturaleza, Olisipo, Pisa, Florencia, Narbona o la propia Valentia son buen ejemplo de ello. Justamente esta variabilidad puede, en muchos casos, permitir la conservación de hallazgos tan importantes y novedosos como los descubiertos en el río Arno. Creemos que ha quedado suficientemente reflejada la necesidad absoluta de llevar a cabo estudios geomorfológicos como los que nos han presentado durante estos días a la hora de abordar una investigación arqueológica sobre cualquier puerto. Esta circunstancia, no hace sino poner sobre la mesa la necesidad, de esta ciencia a que nos dedicamos, de compaginar nuestros conocimientos con los de otras disciplinas. El estudio de estos lugares de intercambio es, por tanto, bastante complejo y así lo hemos visto por ejemplo en Agde y las posibilidades del Herault, o en Dertosa.

Otra de las características más apuntadas de estos puertos es el trasbordo de productos que se produce desde unos barcos a otros mejor adaptados a la navegación fluvial o intraportuaria. En este sentido, quisieramos destacar la extrema importancia de los puertos antiguos como los motores del crecimiento y expansión de las ciudades, aunque también como lugares de penetración de destrucción tal y como nos hicieron recordar en el Algarve, o en Cesaraugusta cuando reclutaban barcazas durante la Guerra entre César y Pompeyo.

En definitiva, ha resultado muy interesante abordar la problemática de los puertos fluviales y pensamos que ha sido enriquecedor para todos nosotros analizar buena parte de los más importantes de la antigüedad. Una conclusión a la que hemos llegado es que al referirnos a estos puertos localizados en las desembocaduras de los ríos o incluso en los cursos medios de los mismos, como Zaragoza y su relación con el puerto de Dertosa, no es posible hacerlo únicamente hablando de puertos fluviales sino más bien de puertos fluviomarítimos. Estos lugares, donde se mezclan las aguas dulces de los ríos con las saladas de la mar, debemos entenderlos como los lugares de intercambio de productos donde éstos se almacenan y redistribuyen. Pero sus Horrea no sólo almacenan productos del o para intercambio, también, son los lugares en los que se produce una confrontación de culturas e ideologías diferentes que, junto a esos productos de intercambio, salen de los Almacenes para impregnar las zonas del interior del área de influencia de cada uno de estos puertos. Son también, cursos fluviales y puertos, los sistemas de comunicación más importantes entre un territorio y su capital, tal y como nos ilustraron en las redes fluviales del Arno y del Tiber para poner en contacto la Etruria interna con su capital. Son, muchas veces, las verdaderas columnas vertebrales de regiones enteras como el caso de Mértola. Son, por tanto, el germen a partir del cual probablemente se haya desarrollado toda esta amplia y riquísima cultura Mediterránea que hoy nos une y por ello debemos actuar para protegerlos. En este sentido, resulta evidente que no podemos negarnos a las necesidades que esta sociedad requiere. No se trata de frenar nuestro desarrollo sino de que éste sea compatible con la salvaguarda del patrimonio, en este caso portuario. Por todo esto, por la importancia que suponen, tanto los puertos actuales para el desarrollo de la economía, como los antiguos por la cantidad de información socio-cultural que almacenan, es necesario actuar conjuntamente para protegerlos y salvaguardarlos de aquellos elementos que puedan afectarlos.

Guillermo Pascual Berlanga José Pérez Ballester Universitat de València

Las $4^{a}$ Jornadas de Arqueología Subacuática -Reunión Internacional sobre Puertos Fluviales Antiguos: Ciudad, Desarrollo e Infraestructurasse celebraron en Valencia los días 28, 29 y 30 de Marzo de 2001 